\title{
EIN ZWISCHEN DE CONSTRUCÃO DE SENTIDO NA AÇÃO DIALÓGICA: OLHAR A DIALOGICIDADE DE FREIRE A PARTIR DA HERMENÊUTICA
}

\author{
EIN ZWISCHEN OF CONSTRUCTION OF SENSE IN THE DIALOGICAL ACTION: \\ LOOKING AT FREIRE'S DIALOGUE FROM HERMENEUTICS \\ EIN ZWISCHEN DE CONSTRUCCIÓN DE SENTIDO EN LA ACCIÓN DIALÓGICA: \\ MIRANDO LA DIALOGICIDAD DE FREIRE A PARTIR DE LA HERMENÊUTICA
}

RESUMO: A Modernidade trouxe um período de racionalização do mundo, levando o ser humano a novas posturas diante do conhecimento. Esse modo de ser moderno passa a não só compreender o mundo como objeto mas também tem uma forte tendência a reduzir o outro a essa condição. Neste estudo, analisamos de que forma o diálogo pode ser compreendido como fundamento ético das relações humanas. Com o intuito de discorrer sobre essa temática, propomos uma interlocução entre Paulo Freire e autores que trabalham na perspectiva hermenêutica. Por meio do estudo, evidenciou-se a centralidade que os autores depositam no diálogo como instrumento de emancipação do homem. Na contramão da proposta de Freire, encontramos o projeto neoliberal que confia na individualidade a tarefa de construção de uma sociedade mais justa e digna, sem perceber que nos únicos monólogos possíveis, na adoção de uma perspectiva tautológica e na (auto)definição que o próprio discurso é o correto, não se abre a possibilidade de construção do Ein Zeischen.

Palavras-chave: Paulo Freire. Dialogicidade. Hermenêutica.

ABSTRACT: The Modernity brought a period of rationalization of the world, taking the human being to new positions before the knowledge. This way of being passes, not only to understand the world as an object, but has a strong tendency to reduce the other to this condition. This way of being passes, not only to understand the world as an object, but has a strong tendency to reduce the other to this condition. With the intention of discussing this theme, we propose an interlocution between Paulo Freire and authors who work in the hermeneutic perspective. Through the study, the centrality that the authors place in the dialogue as an instrument of emancipation of the human being was evidenced. Contrary to Freire's proposal, we find the neoliberal project that relies on individuality for the task of building a more just and dignified society, without realizing that in the only possible monologues, in adopting a tautological perspective and in (self) definition that the self-discourse is the correct, does not open the possibility of building the Ein Zeischen.

Keywords: Paulo Freire. Dialogicity. Hermeneutic.

RESUMEN: La modernidad ha traído un mundo de período de racionalización, lo que lleva al ser humano a nuevas posiciones antes del conocimiento. Esta forma de ser moderno, no sólo para entender el mundo como un objeto, pero tiene una fuerte tendencia a reducir al otro a esta condición. En este estudio, se examinó cómo el diálogo puede ser entendida como una base ética de las relaciones humanas. Con el fin de discutir este asunto, se propone un diálogo entre Paulo Freire y autores que trabajan en la perspectiva hermenéutica. A través del estudio, se demostró la importancia de que los autores ponen en el diálogo como instrumento de emancipación del hombre. Contra la propuesta del Freire, nos encontramos con el proyecto neoliberal que se basa en la individualidad la tarea de construir una sociedad más justa y digna, sin darse cuenta de que los únicos posibles monólogos, la adopción de una perspectiva tautológica y (auto) definición misma la palabra es correcta, no se abre la posibilidad de construcción de Ein Zeischen.

Palabras clave: Paulo Freire. Dialogicidad. La hermenéutica. 
* Doutor em Filosofia - Pontifícia Universidade Católica do Rio Grande do Sul (PUC-RS). Professor do Programa de Pós Graduação em Ensino - Centro Universitário UNIVATES.

** Graduado em Pedagogia - Centro Universitário UNIVATES. Discente do Programa de Pós Graduação em Ensino Centro Universitário UNIVATES. Professor da Rede Municipal de Ensino de Arroio do Meio/RS.

\section{INTRODUÇÃO}

Compreender o diálogo em uma perspectiva freireana, significa afirmar que ele não é entendido apenas mera conversação, mas sim, um fundamento ético e ato de amor ao próximo. Neste estudo, discorremos sobre as possibilidades do diálogo ser compreendido como fundamento ético das relações humanas. Nesse sentido, o que propomos neste artigo nos leva a uma discussão sobre a presença do diálogo na contemporaneidade. Para tanto, buscamos referencial em textos da pedagogia crítica, em especial os escritos por Freire (1979, 1981, 2011a, 2011b, 2011c), bem como autores que estudam o seu pensamento (ZITKOSKI, 2010; ECCO, 2015; ROSSATO; ALVES, 2015). Ainda pretende-se, neste curto espaço, traçar algumas aproximações com autores provenientes da filosofia e da sociologia (HEIDEGGER, 2015; GADAMER, 1997, 2004; BAUMAN, 1997, 1999).

A obra de Freire nos leva ao encontro de fenômenos e acontecimentos que influenciaram os seus escritos, sejam eles econômicos, sociais ou políticos. Streck, Redin e Zitkoski (2010, p. 15), ao apresentarem uma cartografia intelectual do educador, identificam Freire como um menino, que desde a tenra idade buscava uma resposta ao "[...] que ele poderia fazer para o mundo ser menos feio. Um mundo, onde, por exemplo, ninguém mais precisasse sentir o estômago mordendo a si próprio por não ter o que comer".

O Século XX é marcado por uma série de acontecimentos paradoxais, dentre os quais podemos destacar a racionalização da vida cotidiana e do mundo. A Ciência, ao longo dos últimos dois séculos, consolidou-se como a principal forma de leitura e explicação do mundo, em detrimento do saber popular. O projeto moderno, edificado em torno do racionalismo, propunha a utopia de que o desenvolvimento da Ciência oportuniza a melhoria das condições de vida dos sujeitos. Entretanto, o que se percebe, não raro, foi o uso deste conhecimento para a promoção da barbárie. Assim, parece-nos que no mesmo século em que o homem desvendou o íntimo da partícula atômica, da infinitude do universo, do mapeamento da genética, dentre outros feitos, houve um esquecimento radical do Outro.

Se tomarmos os grandes acontecimentos do século passado, como o Holocausto Judeu, os ataques nucleares e os processos de descolonização da África, o esquecimento do Outro torna-se ainda mais evidente. Ao analisarmos esses acontecimentos a partir das discussões de Heidegger (2007, 2015) e Bauman $(1997,1999)$, percebe-se que esses acontecimentos não foram resultantes de momentos de insânia e irracionalismo. Decorrem, muito antes, de uma racionalização do real. Critelli (2012) destaca que, ao longo da Modernidade, a essência da técnica tornou-se a essência do próprio homem, fazendo com que este passasse a não ter acesso ao mundo real, mas sim a uma representação do ente produzida por meio de um procedimento calculador. 
Por não ter acesso à essência do real, a nossa compreensão e ação no mundo passa a ser orientada por uma concepção de custo-benefício, na qual as consequências negativas tornam-se aceitáveis, contanto que os ganhos obtidos por certas ações sejam maiores.

A representação objetificada que tenho do outro leva a existência de situações como a Educação Bancária e a relação de opressores e oprimidos. Em relação à concepção bancária, Freire (2011c, p. 79) afirma que "[...] quanto mais analisamos as relações educador-educando, na escola, em qualquer de seus níveis, parece que mais nos podemos convencer de que estas relações apresentam um caráter especial e marcante - de serem relações fundamentalmente narradoras, dissertadoras". Esse modo de educar, não está somente fundamentado em uma percepção da realidade como objeto estático, mas também em uma suposição de que o outro - educando - é incapaz de ler essa realidade; por isso, é preciso contá-la a ele. Da mesma forma, a relação entre opressores e oprimidos, vista no colonialismo (MEMMI, 2007) e nas relações econômicas (FREIRE, 1979) também se fundamenta em uma ideia do outro como objeto, isto é, alguém que deve ser economicamente ativo e a fim de garantir o lucro dos grupos hegemônicos. Percebe-se que ambos os conceitos remetem a uma ideia de ausência do outro como sujeito, no sentido de não reconhecimento deste.

Ao compreendemos que a ética remete ao cuidado com a nossa morada humana e que ela está assentada no conceito que temos do outro (BAUMAN, 1997; CASALI, 2015), percebemos que o que assistimos ao longo do século passado e, por extensão, no período contemporâneo, aponta para uma crise ética. Percebe-se que o cuidado ético foi contemplado ao avesso no projeto racionalizador da Modernidade, visto que em uma perspectiva tecnocrática de tomada de decisões, a melhor ação a ser seguida é aquela indicada pelo processo calculador. Nesse contexto, a anulação do outro é aceitável e, sobretudo, legítima.

Certamente, o pensamento freireano foi influenciado por esse contexto político, econômico e social, visto que sua obra mais do que uma teorização da realidade é uma "[...] luta humanista e esperançosa por um mundo mais livre e decente para todos" (STRECK; REDIN; ZITKOSKI, 2010, p. 15). Assim, a preocupação central do pensamento de Paulo Freire é a emancipação dos indivíduos e a sua humanização, o que nada mais é do que restituir ao mundo a existência do Outro e dar legitimidade a sua cultura e a sua voz. Se a racionalidade europeia produziu o silenciamento em culturas que fugiam aos parâmetros estabelecidos (SANTOS, 2011), Freire (2001, 2011a) lançou um manifesto a fim de devolver a esses sujeitos o direito de pronunciar-se.

A obra intelectual do autor é um anúncio de esperança. O mundo que Freire (2001) descreve é um mundo 
de possibilidade, e não um mundo acabado. Entretanto, a busca pelo inédito-viável e a superação das situações-limite exige a comunhão de homens, mulheres e crianças oprimidos. Nesse sentido, Freire (2011c) anuncia que o sonho de um mundo melhor é um sonho sonhado coletivamente. O diálogo surge como um princípio, o caminho que permite desvelar a realidade e compreender o jogo de forças econômicas e políticas que a condicionam. Diálogo não é método, mas um princípio ético que deve permear todas as relações humanas. Na primeira seção do nosso estudo, intitulada $\mathrm{O}$ diálogo como princípio ético: o pensamento pedagógico de Paulo Freire, propomos uma revisão conceitual do conceito diálogo.

Após essa imersão conceitual, tornar-se-á visível a proximidade do conceito de diálogo no pensamento de Freire (2011c) e dos escritos de Gadamer (1997, 2004). Enquanto que para Freire (2011c) o diálogo representa a comunhão entre os homens, Gadamer (2004) entende o diálogo como uma experiência de encontro e uma aproximação entre os homens, que possibilitaria o encontro em torno de algo a se postar no meio dos interlocutores, no qual uma nova compreensão da realidade poderá se efetivar. Ambos os autores convergem ao apontar que o diálogo verdadeiro - fundamentado na abertura para a radicalidade do outro - possui uma força transformadora no indivíduo que permite a ele uma constante reconstrução do real no qual está inserido. Essas questões serão aprofundadas na seção Interlocuções entre Freire e Gadamer: A Força transformadora da ação dialógica, em que buscaremos apresentar pontos comuns entre os dois autores.

Por fim, buscamos refletir acerca da temática e dos tópicos apresentadas, destacando a necessidade de criar espaços de comunhão e de diálogo entre os homens, bem como redescobrir o outro. A ausência do outro resulta em opressão, desumanização dos indivíduos e a sua objetificação. Isso pode ser percebido em diversas passagens do pensamento de Freire (2011c), dentre as quais destacamos a educação bancária. Esse cenário, acelerado no contexto contemporâneo, no qual há uma supervalorização do eu individual e uma hiper-racionalização da vida cotidiana, somente tende a ser modificada quando o diálogo estiver presente no contexto do homem. Assim, é preciso reconhecer a importância da ação dialógica em detrimento da monologização.

\section{O DIÁlOGO COMO PRINCÍPIO ÉTICO E O PENSAMENTO PEDAgógico DE PAULO FREIRE}

No pensamento de Paulo Freire, o conceito de diálogo encontra-se onipresente, isto é, um tema que 
perpassa toda sua obra. A humanização e a conscientização dos indivíduos seriam decorrentes de processos dialógicos, nos quais os indivíduos compartilham suas concepções de mundo. Nesse viés, Zitkoski (2010, p. 117) entende que a dialogicidade é "[...] uma das categorias centrais de um projeto pedagógico crítico, mas propositivo e esperançoso em relação a nosso futuro". O diálogo, na perspectiva apresentada, é dotado de uma força transformadora que possibilitará ao indivíduo uma compreensão mais crítica do seu meio.

Todavia, a ação dialógica não está restrita à capacidade de transformação do homem, uma vez que ela é uma necessidade existencial: "[...] se, ao dizer suas palavras, ao chamar o mundo, os homens o transformam, o diálogo impõe-se como o caminho pelo qual os homens encontram seu significado enquanto homens; o diálogo é, pois, uma necessidade existencial" (FREIRE, 1990, p. 83). O homem se reconhece como homem ao pronunciar a sua realidade. Negar a palavra ao homem é impedir que ele assuma sua humanidade perante o mundo. Assim, Santos (2011) destaca, por exemplo, que a Ciência Moderna, ao silenciar a necessidade das culturas dominadas, produziu o que denominou de epistemicídio cultural. A linguagem legitima a existência dos indivíduos e de sua cultura.

As implicações da negação da palavra nos processos de colonização, também foram estudadas por Memmi (2007), quando analisou os processos de mimetismo dos colonizados. Ao negar que cada um expresse sua compreensão singular de mundo, o colonizador leva os indivíduos a um processo de despersonalização: “[...] o que poderíamos chamar de marca do plural. O colonizado jamais é caracterizado de uma maneira diferencial; só tem direito ao afogamento no coletivo anônimo" (MEMMI, 2007, p. 123). Ao negar a palavra ao indivíduo, o colonizador passa a expressar as necessidades dele, assim como também afirma qual a sua identidade. Ao analisar, por exemplo, a relação entre a ociosidade dos indivíduos e o desenvolvimento do contexto que eles vivenciam, o autor destaca que um "[...] retrato místico e degradante termina, em certa medida, por ser aceito e vivido pelo colonizado. Ele ganha assim uma certa realidade, contribuindo para o retrato real do colonizado" (MEMMI, 2007, p. 125).

As duas situações apresentadas evidenciam que "[...] caso onde haja homem, não haja diálogo, então a natureza humana daquele está designificada. O diálogo é coprincípio significativo do homem como tal" (JORGE, 1981, p. 21). Para existir diálogo, é preciso então humildade por parte dos envolvidos, virtude esta que não pode ser confundida com inferioridade e covardia. A humildade, segundo Ecco (2015, p. 181), compreende a uma virtude do pensamento de Paulo Freire que está associada diretamente ao ideário humanizador que "[...] passa pela aceitação das outras pessoas, na sua totalidade/integralidade, bem como estar aberto às suas contribuições”. Humildade é uma prática 
ética de defesa da dignidade do outro e do direito de expressar sua compreensão de mundo e de realidade.

A humildade, que na obra de Paulo Freire também é entendida como uma virtude do educador (ECCO, 2015), é tematizada por Gadamer (2004, p. 250) quando este fala sobre a incapacidade para o diálogo:

Sua forma normal é a de que a pessoa não vê essa incapacidade em si mesma, mas no outro. Dizemos "com você não se pode conversar". E o outro tem a sensação ou a experiência de não ser compreendido. Isso faz com que a pessoa emudeça de antemão ou tranque os lábios, amargurada. Nesse sentido, a incapacidade para dialogar é em última instância sempre o diagnóstico de alguém que não se presta ao diálogo e não consegue entrar em diálogo com o outro. A incapacidade do outro é sempre também a própria incapacidade.

$\mathrm{Na}$ esteira do que vínhamos expondo, Gadamer (2004) corrobora que em um cenário no qual um dos sujeitos possui pressuposições sobre o outro ou o coloca em uma hierarquia axiológica. Freire (2011c, p. 70) emprega essa suposição para elaborar uma crítica ao que ele designou de educação bancária, isto é, aquele modelo de "[...] narração de conteúdos que, por isto mesmo, tendem a petrificar ou a fazer-se algo quase morto, sejam valores ou dimensões concretas da realidade". Nesse viés de educação, o docente narra a sua leitura de mundo e as suas interpretações sobre os fenômenos para os educandos que são compreendidos como objetos ou incapazes pensar sobre a realidade na qual estão inseridos.

Uma educação que subestima a capacidade, a dignidade e leitura de mundo do estudante, não garante a aprendizagem, uma vez que ela somente garante a memorização do perfil do objeto. Nessa forma de educar, Freire (2011a, p. 67) destaca que "[...] o aprendiz funciona muito mais como paciente da transferência do objeto ou do conteúdo do que como sujeito crítico, epistemologicamente curioso, que constrói o conhecimento do objeto ou participa de sua construção". A educação bancária transforma o educando uma espécie de objeto que existe no mundo, mas que não possui capacidade de questionar a sua própria existência, conforme Heidegger (2015). Uma prática pedagógica que compreende o educando como ente, pressupõe a existência de uma hierarquia, na qual, como educador, eu me sinto superior ao estudante com quem trabalho.

Nesse sentido, a educação, na pedagogia de Paulo Freire, não é um ato que o educador possa fazer para os seus educandos, mas uma ação desenvolvida com eles. O processo de conscientização - como veremos posteriormente - é um ato feito em comunhão com os outros, e ao mesmo tempo também individual. Ato coletivo, pois conforme Freire (2011c, p. 95) "[...] ninguém educa ninguém, ninguém educa a si mesmo, os homens se educam entre si, 
mediatizados pelo mundo". O processo de educar exige o diálogo para que possa existir a inter-relação entre os homens. Contudo, a tomada de consciência é um ato individual, na qual eu a construo com a colaboração e em comunhão com os demais homens e mulheres.

Assim, para Freire (1981), se não houver diálogo, não pode haver uma educação que possibilite a tomada de consciência por meio da imersão/emersão na/da realidade. Sem diálogo, o que há aproxima-se mais de um modelo de educação com a predominância de um monólogo, ou fluxo unidirecional de narração, na qual o educador que se julga sábio, doa o saber a aqueles que se consideram ignorantes. Todavia, a proposta dialógica como um fio condutor da prática pedagógica não é uma tarefa simples, mas de extrema complexidade:

O diálogo entre professor e alunos é certamente uma das formas mais primitivas de experiência de diálogo, e aqueles carismáticos do diálogo que falamos acima são todos mestres e professores que ensinam seus discípulos ou alunos através do diálogo. Na situação do professor reside uma dificuldade peculiar em manter firme a capacidade para o diálogo, na qual a maioria sucumbe. Aquele que tem que ensinar acredita dever e poder falar, e quanto mais consistente e articulado por sua fala, tanto mais imagina estar se comunicando com seus alunos. (GADAMER, 2004, p. 248).

Nesse sentido, seria necessário fazer uma retomada da própria constituição da pedagogia e da educação. Significa dizer que, se compreendermos a escolarização como um processo moderno, veremos que os docentes assumiram a postura de anunciar e profetizar o mundo ordenado pela razão, acreditando assim evitar que a animalidade tomasse conta do indivíduo humano (KANT, 2012). Logo, a docência se revestiu deste poder magistral: corrigir e conduzir o homem no uso da razão. A proposta de educação dialógica requer uma reinvenção da docência, da nossa própria concepção de docência.

Essa docência necessária para que a ação dialógica possa ocorrer no interior da escola precisa estar edificada em torno do que Ecco (2015, p. 171) denomina virtudes do pensamento pedagógico de Paulo Freire, sendo elas "[...] a amorosidade, a coerência, a confiança, a curiosidade, a decência, a dialogicidade, o escutar, a esperança, a humildade, o respeito, a simplicidade e a tolerância”. Essas virtudes revelam, segundo Ecco (2015, p. 174), uma ação pedagógica orientada "[...] por princípios e valores humanizadores, isto é, centrada na vida, nos seres humanos (educandos) e não apenas em métodos, técnicas e conteúdos". O que o uso dessas virtudes aponta consiste em uma abertura para com o outro. Essa disposição em contemplar o outro e a sua concepção de mundo em minha prática pedagógica, seria a 
própria predisposição para o diálogo.

Eis que surge a necessidade de pensarmos uma nova concepção de docência. Para tanto, nas primeiras obras pedagógicas podemos perceber as propostas dos Círculos de Cultura e da Educação Popular. Essas propostas evidenciam o pensamento do autor, principalmente ao evidenciar que a educação e conscientização podem ocorrer em outros lugares que não somente no espaço formal da educação. Nesse contexto, a escola formal e suas concepções bancárias de educação deveriam ser compreendidas com certo ceticismo, pois encoberta na sua suposta neutralidade política, eis que mantém inalteradas as estruturas de poder vigentes na sociedade.

Um dos principais desafios para a introdução de práticas dialógicas na contemporaneidade consiste em superar a existência dos "púlpitos onipresentes" (MORAIS, 2006) que existem no interior das salas de aula. Ao superar-se essa onipresença da hierarquização entre educador e educando, abrem-se as possibilidades de aproximarmo-nos de um pensamento pensante, "[...] não um pensamento pensado. Trata-se, como sempre, de um pensar dialogante, por isso processual e a mais vozes, inclusive as do povo" (BOFF, 2007, p. 6). O diálogo efetivo, que implica a abertura ao outro, ao seu modo de compreender a realidade, nos leva ao encontro em torno de algo, sendo que é condição de possibilidade para construir esse pensar dialogante.

Por fim, queremos ainda lembrar que Guareschi (1991a) e Gadamer (2004) identificam duas situações que favorecem a monologização do real. Mesmo os exemplos apresentados pelos autores sendo diferentes, elas convergem para um mesmo indicador: a tecnologização do real. Guareschi (1991a, p. 16), afirma que assistimos a uma construção da realidade por meio da comunicação social, ou seja, os meios de comunicação “[...] são fator indispensável tanto na criação como na transmissão, mudança, legitimação e reprodução de determinada cultura. Em cada filme, novela, propaganda etc., há um pano de fundo, um background cultural". Ao criarem esse mundo e o apresentarem como sendo superior ao mundo real, no qual vivemos, a comunicação social acaba anulando formas de vida e apresentando um ideal de homem. As especificidades culturais e sociais raramente são apresentadas e legitimadas. Homens e mulheres que vivem à margem da sociedade, não se sentem dignos de pronunciar seus modos de ser. Destarte, a presença do diálogo vivo, no contexto educacional, exige o reconhecimento do modo de viver do outro.

Por sua vez, Gadamer (2004, p. 244) sustenta a tese de que os dispositivos de comunicação nos dão uma falsa percepção de que somos sujeitos de diálogo. O autor cita, por exemplo, a conversa telefônica que leva inevitavelmente "[...] a um empobrecimento comunicativo que se dá na convivência com as pessoas que se encontram ao nosso lado, restringindo-se ao elemento acústico”. Dessa forma, a presença das tecnologias de comunicação e informação, 
cada vez mais presentes no cotidiano, não raramente podem vir a atrapalhar a vivência de experiências de aproximação mútua.

O que se percebe é que, no pensamento pedagógico de Paulo Freire, o diálogo é mais do que uma escolha metodológica que os educadores devem se valer para promover a conscientização dos sujeitos. Nas próprias palavras de Freire (2011b, p. 166), "[...] o diálogo é a possibilidade de que disponho de, abrindo-me ao pensar dos outros, não fenecer no isolamento". Com base nesses pressupostos, partimos rumo à reflexão sobre algumas situações-limite existentes para a ocorrência do diálogo no contexto contemporâneo. Merece destaque especial a presença de púlpitos onipresentes na sala de aula, que levam a disposição hierárquica dos sujeitos em relação ao seu conhecimento. Outro fator é a virtualização do real, que mais atrapalha do que impulsiona a abertura mútua com o outro que é real. Na próxima seção, buscamos mais aproximações entre o pensamento de Paulo Freire e Hans Georg Gadamer.

\section{INTERLOCUÇÕES ENTRE FREIRE E GADAMER E A FORÇA TRANSFORMADORA DA AÇÃO DIALÓGICA}

Mais do que um método para a alfabetização de jovens e adultos, em Freire o diálogo é um princípio ético e um ato de amor ao outro e à humanidade. Dialogar refere-se, assim, a um ato de expor a percepção de mundo. Há algo de transformador inerente ao diálogo. Essa potência transformadora do diálogo é reconhecida na pedagogia crítica como "[...] a força que impulsiona o pensar crítico-problematizador em relação à condição humana no mundo" (ZITKOSKI, 2010, p. 117). Para Gadamer (2004, p. 247): “um diálogo é, para nós, aquilo que deixou uma marca”. Frente a isso, urge identificar o que o diálogo produz em seus participantes.

Necessitamos retomar dois pressupostos que Freire (2011c) apresenta ao longo de sua obra acerca da educação. Primeiro: Educação não consiste apenas na memorização mecânica de um conjunto de códigos, nem o domínio mecânico da capacidade de decodificação. Educação é uma práxis de leitura de mundo e de palavras, que possibilitam o desenvolvimento de uma consciência crítica e a emancipação do indivíduo (FREIRE, 1979, 1981, 2011a, 2011c). O segundo pressuposto aponta par ao fato de que o processo de conscientização não é um processo individual, mas sim um ato coletivo: "[...] os homens se educam em comunhão, mediatizados pelo mundo. Mediatizados pelos objetos cognoscíveis que, na prática bancária, são possuídos pelo educador que os descreve ou os deposita nos educandos passivos" (FREIRE, 2011c, p. 96). A educação se dá em comunhão, na qual os homens se educam, visto que o diálogo é condição de possibilidade para a efetivação da educação. 
O fundamento primeiro da pedagogia crítica é a libertação e esta não ocorre se "[...] não houver consciência da figuração de mundo ideológica e enquanto essas instituições coercitivas básicas estivessem imunes à livre discussão e a crítica" (GUARESCHI, 1991b, p. 54). A educação de homens e mulheres inexiste se não ocorrer concomitante com o sonho de mudar de vida (FREIRE; NOGUEIRA, 2007, p. 21). A teoria crítica da pedagogia compreende que a educação pode resultar em uma mudança da realidade. Dessa forma, o que se busca não é somente o ensino de uma cultura letrada, mas, sobretudo, a criação de mecanismos que visam ao empoderamento dos sujeitos e a transformação da consciência ingênua em uma consciência crítica.

A critização da consciência, a emancipação de homens e mulheres e o desenvolvimento da curiosidade sistêmica são desenvolvidos, segundo Freire (2011b, 2011c), por meio da educação problematizadora e que tem no diálogo o seu fundamento principal. Logo, percebe-se a confiança depositada no diálogo como instrumento capaz de formar homens e mulheres. Zitkoski (2010, p. 117) entende que o educador brasileiro "[...] retoma a concepção do diálogo como processo dialético-problematizador [...]. Através do diálogo podemos olhar o mundo e a nossa existência em sociedade como processo, algo em construção, como realidade inacabada e em constante transformação". A primeira premissa orientadora dessa perspectiva, é que, por meio do diálogo, homens e mulheres são convidados a pronunciar sua compreensão de mundo e sua condição enquanto sujeitos.

O que homens e mulheres expõem inicialmente é a sua leitura de mundo, isto é, sua compreensão da realidade e entendimento sobre os fenômenos (FREIRE, 1988). Esse entendimento, muitas vezes, é uma consciência mínima e resulta em uma leitura limitada do mundo. Loiola e Borges (2013, p. 297) sustentam que, ao trabalhar com classes sociais marginalizadas, percebe-se que sua "[...] percepção do mundo é limitada por preocupações elementares com tudo o que é vital, no sentido biológico do termo". A compreensão do mundo, no qual se está inserido, é muitas vezes justificada pelo fato da presença de uma entidade transcendental. Essas explicações "mágicas" do mundo, despotencializam homens e mulheres que poderiam agir em prol da transformação.

Em uma compilação póstuma de seus escritos, Freire (2001) destaca a função que o sonho e a utopia exerciam nessa transformação, visto que elas serviam essencialmente como um fator motivador em busca desta. Segundo Gadamer (2004, p. 246): “[...] o diálogo com os outros, suas objeções ou sua aprovação, sua compreensão ou seus mal entendidos, representam uma espécie de expansão de nossa individualidade e um experimento da possível comunidade a que nos convida a razão". 
A tomada de consciência da realidade de oprimido faz exige uma relação dialógica na qual esteja presente o conflito, porque, pelo contrário, se corre o risco de desenvolver um diálogo ingênuo ou a simples conversação (GADOTTI, 2003). A comunhão dos homens e mulheres no momento do diálogo permite que os sujeitos possam "[...] encontrar-se e construir aquela espécie de comunhão onde cada qual continua sendo o mesmo para o outro porque ambos encontram o outro e encontram a si mesmos no outro" (GADAMER, 2004, p. 247). A força do diálogo reside nessa possibilidade de mergulho em uma experiência social na qual se efetiva um "[...] entregar-se a um processo social aberto; o reconhecimento mútuo da autonomia dos parceiros, a capacidade de ouvir um ao outro; sua interdependência no sentido de aceitarem que somente juntos chegarão a um resultado construtivo" (FLICKINGER, 2014, p. 85).

O diálogo exige a presença e disposição do outro, para que ocorra um processo semelhante ao jogo, isto é, um momento "[...] em que cada um dos interlocutores aceita o desafio lançado pela pergunta do outro. Cada reação, por sua vez, torna-se novo desafio, de modo que o processo continua sem repouso o seu desdobramento" (FLICKINGER, 2014, p. 84). Na mesma direção caminha a argumentação de Freire (2011a, p. 98), quando afirma que "partir do saber de experiência feito para superá-lo não é ficar nele”. A experiência inicial de mundo, a primeira leitura de mundo, torna-se um estímulo para iniciar o diálogo. Nesse sentido, poderíamos destacar, por exemplo, as palavras geradoras (FREIRE, 1979, 1981, 1990) que são o fio condutor da conversa. O que se espera é que a palavra geradora conduza o diálogo para além daquilo que os integrantes já sabem ou conhecem. O dito, as interrogações sobre aquilo que foi exposto, o ir e vir dos argumentos expostos vão criando espaços de emergência no dito e não dito no diálogo, com base no qual os parceiros envolvidos no diálogo podem se (auto)interrogar e (auto)refletir sobre a própria leitura de mundo, produzindo assim, um novo saber sobre o mundo.

$\mathrm{Na}$ comunhão que homens e mulheres estão imersos quando envolvidos em uma ação dialógica, o interlocutor "[...] é o incentivo que nos faz refletir sobre a nossa opinião atual. E o refletir, na sua interpretação literal, significa aceitar o outro como o espelho que nos devolve a imagem de nós mesmos" (FLICKINGER, 2014, p. 85). Por meio da experiência dialógica com o outro, é possível encontrar algo que "ainda não havíamos encontrado em nossa própria experiência de mundo" (GADAMER, 2004, p. 247). A problematização e o conflito presente no diálogo me servem como estímulo para realizar uma releitura do mundo no qual estamos inseridos. O diálogo produz o que Gadamer (1997) denominou de Ein Zwischen, isto é, um entre, um encontro em torno de algo que abre o espaço no qual pode emergir uma nova compreensão do real e da própria existência. 
É nesse espaço entre, em que homens e mulheres se encontram em "comum-união". Esta "[...] fá-los-ia descobrir a sua vocação histórica e, arrancando-os à imersão em que estavam jogados, levá-los-ia a uma participação e uma responsabilidade social e política nas coisas do próprio país" (JORGE, 1981, p. 11). O diálogo possibilita a tomada de consciência com o real; final, por meio da ação coletiva com o outro vai se construindo uma consciência mais crítica, que, como já dito anteriormente, liberta da ingenuidade e das explicações mágicas do mundo. Visto que a ação do homem é reflexo do nível de sua consciência (FREIRE, 1990, 2001), ao perceber que a realidade é uma construção histórica e que muitos dos fenômenos até então explicados de modo mágico são resultados de condicionantes políticos e econômicos, surge um sentimento de empoderamento e uma percepção de que é possível assumir a autoria da própria história (FREIRE, 2001).

Quando Freire (1981, 2011b) afirma que para haver educação é preciso que haja homens e mulheres dispostos a entrar em comunhão, é precisamente pelo fato de ele perceber que individualmente ou nos monólogos não se abre espaço para Ein Zwischen; logo, não se produzem novos sentidos. A ação monóloga e o fluxo unidirecional de comunicação e informação são pura tautologia, na qual se repete o dito, sem possibilidade de construção de novos sentidos.

Por fim, queremos destacar ainda a questão da identidade presente no diálogo, em especial, quando retomamos o pensamento de Memmi (2007). O autor denomina a perda da própria identidade de mimetismo cultural, em decorrência de um processo de culturalização. O mesmo pode ser percebido no pensamento de Freire (2011b, 2011c), quando aborda o processo de desumanização e objetificação do homem, que denomina como sendo uma perda de sua essência. Uma visão superficial do diálogo também poderia ser compreendida dessa forma, considerando que a leitura de mundo inicial vai sendo abandonada em favor de uma leitura mais crítica da realidade. Contudo, Gadamer (1997, p. 446) afirma que "[...] por mais que alguém se desloque a uma forma espiritual estrangeira, nunca chega a esquecer a sua própria acepção de mundo e inclusive da linguagem". Assim, no processo de produção de uma nova compreensão de mundo decorrente da comunhão com o(s) outro(s), o sujeito que até então fazia uma leitura ingênua da realidade adquire consciência de sua situação existencial.

A conservação da identidade por meio do diálogo em detrimento do mimetismo também é assumida por Freire (2011b, p. 163), quando este afirma que "[...] o diálogo tem significação precisamente porque os sujeitos dialógicos não apenas conservam sua identidade, mas a defendem e assim crescem um com o outro. O diálogo, por isso mesmo, não nivela, não reduz um ao outro". A proposição fundante do diálogo é o respeito radical ao outro e o seu reconhecimento como tal. Ele não é reduzido a um espectador, mas 
alguém que é colocado em uma condição de igualdade. É por meio da efetivação do diálogo que "[...] se espelha a totalidade do mundo, e a totalidade do mundo que se apresenta nos pontos de vista individuais de todos os outros como um e o mesmo" (GADAMER, 2004, p. 246).

\section{CONSIDERAÇÕES FINAIS}

O diálogo exige dos homens a humildade e o reconhecimento do outro. A precondição para a existência do diálogo entre os indivíduos é que ambos reconheçam a sua incompletude enquanto sujeitos e a existência de condicionantes sobre seus modos de ser no mundo. O outro, tanto para Freire (2011a) como para Gadamer (2004), é condição essencial para que ocorra o diálogo. Contemporaneamente a individualização dos sujeitos, decorrente da consolidação do neoliberalismo como sistema econômico hegemônico (MÉSZÁROS, 2002) e a racionalização da vida cotidiana, faz com que a essência do ser seja resultante de um processo calculador. Neste contexto, o ser se oculta, e somos impelidos a uma mera representação do ente (HEIDEGGER, 2015).

Somos cada vez mais desafiados a discutir as contribuições de Paulo Freire para a educação contemporânea e impelidos a revisitar o conceito de diálogo e as suas contribuições para pensarmos a contemporaneidade. Segundo Freire (1981, p. 43), "[...] uma das grandes, senão a maior tragédia do homem moderno, está em que hoje é dominado pela força dos mitos e comandado pela publicidade organizada, ideológica ou não, por isso vem renunciando cada vez à sua capacidade de decidir”. Mesmo depois de quase quatro décadas desde a constatação do educador brasileiro, parece que o cenário social não teve significativas alterações. Participamos da promessa de que o esclarecimento traria a emancipação e libertação de homens e mulheres. Assistimos, desde meados da década de 1990, ao discurso de que o acesso à informação e comunicação elevará o espírito humano, por meio da difusão do conhecimento em tecnologias digitais. No entanto, percebe-se uma maior individualização dos sujeitos. Os espaços de comunhão e diálogo tornam-se cada vez mais ausentes, não só no ambiente social, escolar, mas também no familiar e outros mais.

Ao revisitarmos a obra de Paulo Freire, a fim de identificar as funções que este confiava ao diálogo, evidenciou-se a centralidade que devemos depositar no diálogo como instrumento para a emancipação do homem. Sem diálogo não há comunhão, não há sonho coletivo, nem pensamento dialogante. Na contramão da proposta de Freire, percebe-se que o projeto neoliberal confia na individualidade a tarefa de construção de um projeto de sociedade mais justo e digno, sem perceber que nos únicos monólogos possíveis, na adoção de uma perspectiva 
tautológica e na (auto)definição que o próprio discurso é o correto, não se abre a possibilidade de construção do Ein Zeischen, pelo contrário, fecha-se o espaço do encontro em torno de algo.

Ao comentar a relação existente entre o pensamento de Paulo Freire e a hermenêutica, Bombassaro (2010, p. 204) destaca que ambos convergem ao apontar que "[...] situado no mundo, relacionando-se com a natureza, com os outros e consigo mesmo, o homem toma consciência da realidade que o cerca e desenvolve, ao mesmo tempo a consciência de si, a autoconsciência”. Logo, a individualização do sujeito não permite a ele essa relação com o outro e, em decorrência disso, diminui as possibilidades de tomada de consciência de si e da realidade. $O$ fechar-se em si e a negação da existência do outro, quando operamos sob uma lógica de compreender o outro por meio do processo calculador, faz com que nós mesmos não consigamos nos perceber como sujeitos. Em conformidade com o pensamento de Heidegger (2015), poderíamos afirmar que aí se dá o fechamento do processo de desocultamento, desvelamento, do Dasein.

Ao que ficou evidenciado até aqui, grande parte dos problemas contemporâneos podem ser explicados e compreendidos por causa do esquecimento do outro. Nesse sentido, as contribuições da obra freireana nos lançam frente a essa necessidade do encontro com outro por meio do diálogo. Por tudo que foi exposto, podemos afirmar que o diálogo pode ser compreendido como condição de possibilidade para a construção de uma sociedade mais humana.

\section{REFERÊNCIAS}

BAUMAN, Zygmunt. Modernidade e Ambivalência. Rio de Janeiro: Zahar, 1999.

BAUMAN, Zygmunt. Ética Pós Moderna. São Paulo: Paulus, 1997.

BOMBASSARO, Luiz Carlos. Hermenêutica. In: STRECK, Danilo; REDIN, Euclides; ZITKOSKI, Jaime José. Dicionário Paulo Freire. Belo Horizonte: Autêntica, 2010. p. 204-205.

BOOF, Clodovis. Apresentação. In: FREIRE, Paulo; NOGUEIRA, Adriano. Teoria e prática em Educação Popular. 7. ed. Petrópolis: Editora Vozes, 2007. p. 3-8.

CRITELLI, Dulce. Martin Heidegger e a essência da técnica. Revista Margem. Dossiê: Consciências do Mundo Martin Heidegger e a essência da técnica, São Paulo, n. 16, p. 83-89, dez. 2002. 
ECCO, Idanir. Do legado freireano: virtudes docentes para a educação humanizadora. In: DALLA COSTA, Antônio Amélio; ZARO, Jandir; SILVA, Jolair da Costa (Org.). Educação Humanizadora e os desafios éticos na sociedade pós-moderna. Santa Maria: Biblios, 2015. p. 171-190.

FLICKINGER, Hans-Georg. Gadamer e a Educação. Belo Horizonte: Autêntica, 2014.

FREIRE, Paulo. Educação como prática de liberdade. 12. ed. Rio de Janeiro: Ed. Paz e Terra, 1981.

FREIRE, Paulo. A importância do ato de ler: em três artigos que se completam. São Paulo: Autores Associados: Cortez, 1988.

FREIRE, Paulo. Ação cultural para a liberdade. 4. ed. Rio de Janeiro: Paz e Terra, 1979.

FREIRE, Paulo. Conscientização Teoria e Prática da Libertação: uma introdução ao pensamento de Paulo Freire. São Paulo: Centauro, 1990.

FREIRE, Paulo. Pedagogia dos sonhos possíveis. São Paulo: UNESP, 2001.

FREIRE, Paulo. Pedagogia da Autonomia: saberes necessários à prática educativa. São Paulo: Paz e Terra, 2011a.

FREIRE, Paulo. Pedagogia da esperança: um reencontro com a pedagogia do oprimido. São Paulo: Paz e Terra, 2011b.

FREIRE, Paulo. Pedagogia do Oprimido. São Paulo: Paz e Terra, 2011c.

FREIRE, Paulo; NOGUEIRA, Adriano. Teoria e prática em Educação Popular. 7. ed. Petrópolis: Editora Vozes, 2007.

GADAMER, Hans-Georg Verdade e Método I. Petrópolis: Vozes, 1997.

GADAMER, Hans-Georg. Verdade e Método II: complementos e índices. 2. ed. Petrópolis, RJ: Vozes, 2004.

GADOTTI, Moacir. Prefácio. In: FREIRE, Paulo. Educação e Mudança. 27. ed. São Paulo: Paz e Terra, 2003. p. 9-14.

GUARESCHI, Pedrinho Arcides. A realidade da comunicação - visão geral do fenômeno. In: GUARESCHI, 
Pedrinho Arcides (Coord.). Comunicação e Controle Social. Petrópolis: Vozes, 1991a. p. 13-22.

GUARESCHI, Pedrinho Arcides. Comunicação e Teoria Crítica. In: GUARESCHI, Pedrinho Arcides (Coord.). Comunicação e Controle Social. Petrópolis: Vozes, 1991b. p. 52-71.

HEIDEGGER, Martin. A questão da técnica. Scientiæ Studia, São Paulo, v. 5, n. 3, p. 375-98, 2007.

HeIDEGGER, Martin. Ser e Tempo. Petrópolis: Vozes, 2015.

JORGE, Jacinto. Simões. Sem ódio nem violência: A perspectiva da libertação segundo Paulo Freire. São Paulo: Edições Loyola, 1981.

KANT, Immanuel. Sobre a Pedagogia. Lisboa: Edições 70, 2012.

LOIOLA, Francisco A.; BORGES, Cecília. A pedagogia de Paulo Freire ou quando a educação se torna um ato político. In: GAUTHIER, Clermont; TARDIF, Maurice (Org.). A pedagogia - teorias e práticas da Antiguidade aos nossos dias. Tradução de Lucy Magalhães. Petrópolis: Vozes, 2013. p. 287-309.

MEMMI, Albert. Retrato do colonizado precedido pelo retrato do colonizador. Rio de Janeiro: Civilização Brasileira, 2007.

MÉSZAROS, I. Para além do capital: rumo a uma teoria da transição. São Paulo: Boitempo, 2002.

MORAIS, Regis de. Entre a jaula de aula e o picadeiro. In: MORAIS, Regis de. Sala de Aula: que espaço é esse? Campinas: Papirus, 2006. p. 17-30.

ROSSATO, Ricardo; ALVES, Marcos Alexandre. Educação ética em tempos Pós-modernos. In: DALLA COSTA, Antônio Amélio; ZARO, Jandir; SILVA, Jolair da Costa (Org.). Educação Humanizadora e os desafios éticos na sociedade pós-moderna. Santa Maria: Biblios, 2015. p. 135-152.

SANTOS, Boaventura de Sousa. Para um novo senso comum: a ciência, o direito e a política na transição paradigmática. São Paulo: Cortez, 2011.

STRECK, Danilo; REDIN, Euclides; ZITKOSKI, Jaime José. Paulo Freire: uma breve cartografia intelectual. In: 
STRECK, Danilo; REDIN, Euclides; ZITKOSKI, Jaime José. Dicionário Paulo Freire. Belo Horizonte: Autêntica, 2010. p. 15-22.

ZITKOSKI, Jaime José. Diálogo/Dialogicidade. In: STRECK, Danilo; REDIN, Euclides; ZITKOSKI, Jaime José. Dicionário Paulo Freire. Belo Horizonte: Autêntica, 2010. p. 117-118.

Recebido em: 17/04/2017 Aprovado em: 10/07/2017 